\title{
Vibrational Order, Structural Properties, and Optical Gap of ZnO Nanostructures Sintered through Thermal Decomposition
}

\author{
Alejandra Londono-Calderon, Fernando F. Jurado-Lasso, Juan D. Romero-Salazar, \\ Nathaly Jurado-Lasso, and J. Fabian Jurado
}

Laboratorio de Propiedades Térmicas Dieléctricas de Compositos, Departamento de Física y Química, Universidad Nacional de Colombia, A.A. 127, Manizales, Colombia

Correspondence should be addressed to J. Fabian Jurado; jfjurado@unal.edu.co

Received 6 June 2014; Revised 15 August 2014; Accepted 15 August 2014; Published 15 September 2014

Academic Editor: Shadi A. Dayeh

Copyright (C) 2014 Alejandra Londono-Calderon et al. This is an open access article distributed under the Creative Commons Attribution License, which permits unrestricted use, distribution, and reproduction in any medium, provided the original work is properly cited.

\begin{abstract}
The sintering of different $\mathrm{ZnO}$ nanostructures by the thermal decomposition of zinc acetate is reported. Morphological changes from nanorods to nanoparticles are exhibited with the increase of the decomposition temperature from 300 to $500^{\circ} \mathrm{C}$. The material showed a loss in the crystalline order with the increase in the temperature, which is correlated to the loss of oxygen due to the low heating rate used. Nanoparticles have a greater vibrational freedom than nanorods which is demonstrated in the rise of the main Raman mode $E_{2}$ (high) during the transformation. The energy band gap of the nanostructured material is lower than the $\mathrm{ZnO}$ bulk material and decreases with the rise in the temperature.
\end{abstract}

\section{Introduction}

Zinc oxide is one of the most promising semiconductors of group II-VI for manufacturing technological devices on a nanometric scale. Since the surface/volume ratio in nanostructures is higher than in bulk materials, the quantum effects dominate the properties. The precise control between morphology and the desired properties has been used in the study and fabrication of gas nanosensors [1-3], light emitting diodes [4], solar cells [5-7], field effect transistors [8], and in photocatalysts [9-11] among others [12]. Throughout the pursuit of these objectives, a wide diversity of sintering techniques have been implemented. Lower cost methodologies, such as thermal decomposition, are the ones positioned in the first place. The thermal decomposition method is an endothermic process where heat is used to break the links within the initial precursor in order to obtain one or more final components. It has been found that this technique allows the growth of nanoparticles [13-16], nanowires, and nanorods [17-19] among others [20]. Zinc acetate decomposes into zinc oxide when being subjected to thermal treatments, generally above $200^{\circ} \mathrm{C}$. This methodology provides an advantage compared to other methods due to the simplicity and the fact that it does not require reducing or additive agents. To obtain zinc oxide through thermal decomposition, some methodologies have reported results as a function of the decomposition temperature, time, and the aging $[16,19,21-24]$. However the relationship between morphology, structural, vibrational, and optical properties and the decomposition process is still not clear. In this work, $\mathrm{ZnO}$ nanostructures have been sintered from the thermal decomposition of zinc acetate at three different temperatures $\left(300,400\right.$, and $\left.500^{\circ} \mathrm{C}\right)$ for a low heating rate and a long annealing time. The morphological, structural, vibrational, and material optical gap variations are being studied.

\section{Experimental Details}

The sinterization of $\mathrm{ZnO}$ nanostructures is as follows: $0.5 \mathrm{~g}$ of zinc acetate dihydrate $\left(\mathrm{Zn}\left(\mathrm{CH}_{3} \mathrm{COO}\right)_{2} \cdot 2 \mathrm{H}_{2} \mathrm{O}\right.$ Sigma Aldrich $98+\%)$ is ground in a mortar for 5 minutes; the powdered material is placed in a crucible, which is inserted in a programmable furnace and heated at a rate of $100^{\circ} \mathrm{C} / \mathrm{h}$ to a temperature of 300,400 , and $500^{\circ} \mathrm{C}$ for a period of 24 hours. The final product is approximately $0.15 \mathrm{~g}$ of $\mathrm{ZnO}$, which is 
stored within a controlled environment for its respective characterization.

The structural characterization was carried out by using a Bruker D8 Advance X-Ray diffractometer (radiation of $\mathrm{CuK}_{\alpha}, \lambda=1,5406 \AA$ ); the vibrational order was assessed through Raman microscopy by using $\mu$-Raman Confocal LabRam HR Horiba Jobin Yvon equipment with a monochromatic laser source of $473 \mathrm{~nm}$. The optical gap was established from absorption by using a UV/Vis Perkin Elmer Lambda 20 spectrophotometer. The morphology was identified by the use of a Transmission Electron Microscope (TEM) JEOL 2010-F working at $200 \mathrm{kV}$ and a Scanning Electron Microscope (SEM) Hitachi 5500 at $30 \mathrm{kV}$.

The change of the morphology of $\mathrm{ZnO}$ sintered by thermal decomposition of zinc acetate has already been reported [22-24]. Farbod and Jafarpoor [22] report an increase in oxygen deficiency with the annealing time and the final color of the sample. Each increment of the temperature leads to an increase in the total sinter time; for $500^{\circ} \mathrm{C}$ the long heating time ( 5 hours) may be responsible for a oxygen deficiency in the final sample. This is also related to the color of the powder which changes from white at $300^{\circ} \mathrm{C}$ to pale yellow at $500^{\circ} \mathrm{C}$.

\section{Results and Discussion}

The thermodynamic mechanism of the zinc acetate decomposition into $\mathrm{ZnO}$ is well known. Initially, the loss of 2 water molecules is observed. The anhydrous acetate reacts with water in the environment to form a basic zinc acetate and acetic acid $\mathrm{CH}_{3} \mathrm{COOH}$. In the decomposition of zinc complex, $4 \mathrm{ZnO}$ molecules, acetate $\mathrm{CH}_{3} \mathrm{COCH}_{3}$, and carbon dioxide $\mathrm{CO}_{2}$ are produced $[18,25]$. The reaction is as follows:

$$
\begin{aligned}
\mathrm{Zn}\left(\mathrm{CH}_{3} \mathrm{COO}\right)_{2} \cdot 2 \mathrm{H}_{2} \mathrm{O} \longrightarrow & \mathrm{Zn}\left(\mathrm{CH}_{3} \mathrm{COO}\right)_{2}+2 \mathrm{H}_{2} \mathrm{O} \uparrow \\
4 \mathrm{Zn}\left(\mathrm{CH}_{3} \mathrm{COO}\right)_{2}+2 \mathrm{H}_{2} \mathrm{O} \longrightarrow & \mathrm{Zn}_{4} \mathrm{O}\left(\mathrm{CH}_{3} \mathrm{COO}\right)_{6} \\
+ & 2 \mathrm{CH}_{3} \mathrm{COOH} \uparrow \\
\mathrm{Zn}_{4} \mathrm{O}\left(\mathrm{CH}_{3} \mathrm{COO}\right)_{6} \longrightarrow & 4 \mathrm{ZnO}+3 \mathrm{CH}_{3} \mathrm{COCH}_{3} \uparrow \\
+ & 3 \mathrm{CO}_{2} \uparrow
\end{aligned}
$$

The variation in the properties of the $\mathrm{ZnO}$ during this process must be correlated to the combination of decomposition temperature, heating rate, and time used for the experiment. For our case of study, Figure 1 shows TEM and SEM images of the material obtained at a fixed heating rate at a temperature of $(\mathrm{a}-\mathrm{d}) 300,(\mathrm{e}-\mathrm{h}) 400$, and $(\mathrm{i}-\mathrm{l}) 500^{\circ} \mathrm{C}$. The sample sintered at $300^{\circ} \mathrm{C}$ is mainly formed by nanorod structures with an average diameter of $35 \pm 10 \mathrm{~nm}$ and an average length of $400 \pm 196 \mathrm{~nm}$. The preferential growth of the nanorods is in the (0001) direction. A high dispersion in the size of the nanorods is observed (inset Figures 1(a) and 1(b)). A low heating rate produces a more achievable loss of water molecules, which are essential in the decomposition process of the zinc acetate [22]. During the formation of hexagonal $\mathrm{ZnO}$, the polar faces (0001) are unstable and have a faster growth rate than the nonpolar faces. By the time the temperature has reached the $300^{\circ} \mathrm{C}$ there is a lack of
TABLE 1: Lattices parameters and crystallite size.

\begin{tabular}{lccc}
\hline Temperature $\left({ }^{\circ} \mathrm{C}\right)$ & $a(\AA)$ & $c(\AA)$ & $D(\AA)$ \\
\hline 300 & 3.247 & 5.202 & $247 \pm 21$ \\
400 & 3.252 & 5.212 & $180 \pm 11$ \\
500 & 3.254 & 5.210 & $195 \pm 9$ \\
\hline
\end{tabular}

nucleation sites, and the long period of time of the annealing promotes then the growth of rod-like structures orientated along the $c$ axis.

For the sample collected at $400^{\circ} \mathrm{C}$ a change in the morphology is observed. The resulting nanostructures are a combination of nanorods and nanoparticles. The average sizes of the nanoparticles are $48 \pm 13 \mathrm{~nm}$ (inset Figure 1(g)) whereas the nanorods have an average diameter of $34 \pm 9 \mathrm{~nm}$ with an average length of $332 \pm 88 \mathrm{~nm}$ (inset Figures 1(e)-1(f)). Once the temperature has increased to $500^{\circ} \mathrm{C}$, hexagonal-like nanoparticles of $104 \pm 22 \mathrm{~nm}$ are observed (inset Figure 1(i)). A higher temperature creates more nucleation sites of which nanoparticles can start to grow, producing a higher consumption of the precursor, favoring a homogeneous growth in all the directions of the hexagonal structure and lead the transformation from nanorods to nanoparticles.

3.1. Structure. Figure 2 shows the XRD diffractograms for the treated material at 300,400 , and $500^{\circ} \mathrm{C}$, respectively. All the diffraction peaks correspond to the hexagonal phase of the $\mathrm{ZnO}$ according to JCPDS card number 36-1451; no impurity peaks were detected. The lattice parameters were established through the Cohen method and the mean crystallite size $(D)$ was determined by the use of Scherrer's equation:

$$
D=\frac{0.9 \lambda}{\beta \cos \theta},
$$

where $\lambda$ is the wavelength of the $\mathrm{X}$-ray radiation and $\beta$ is the full width at half maximum (FWHM) of each diffraction peak. The different values for $D$ and the lattice parameters are presented in Table 1.

It is observed that the temperature has an influence on crystallite domain size. Narrow peaks are present in the $300^{\circ} \mathrm{C}$ sample in which the crystallite size is comparable to the diameter of the nanorods. This may imply that the nanorods are formed by groups of crystallite pilled-up along the growth axis $c$. An increment in the FWHM value and a decrease in the relative intensity of the peaks are observed for the higher temperature of $500^{\circ} \mathrm{C}$. At this temperature there are more nucleation sites that allow the growth of nanoparticles formed by random arrangements of smaller crystallites. Increasing the temperature does not promote grain boundary diffusion; as a result a loss in the crystalline order is observed. $\mathrm{ZnO}$ has a tendency to lose oxygen [26], during the heating time before reaching the annealing temperature of $500^{\circ} \mathrm{C}$ in which more water escapes from the furnace and it is more likely to obtain a nonstoichiometric material.

3.2. Micro-Raman. Figure 3 shows the micro-Raman spectra results of the obtained materials as well as the $\mathrm{ZnO}$ reference. 


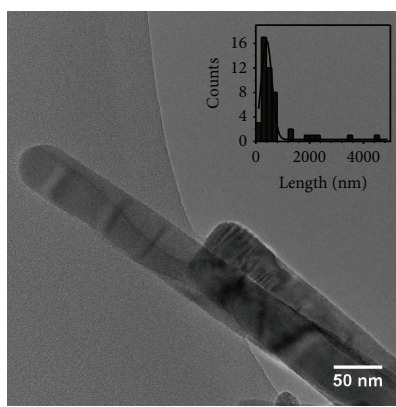

(a)

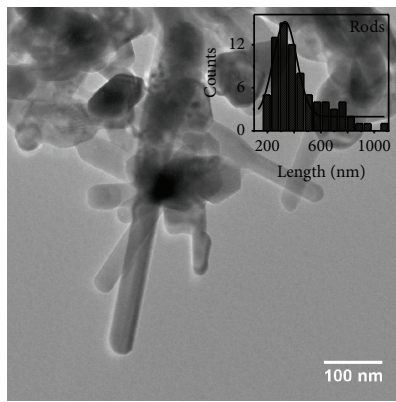

(e)

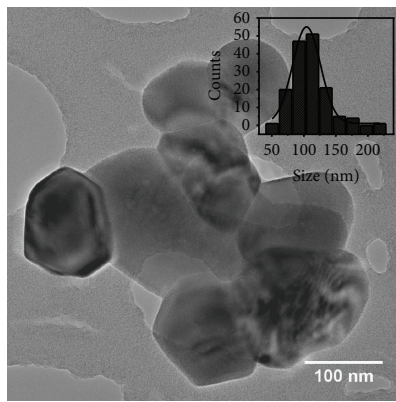

(i)

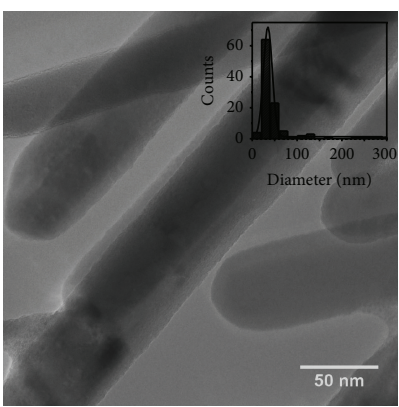

(b)

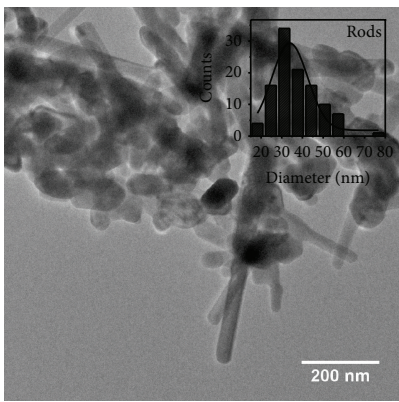

(f)

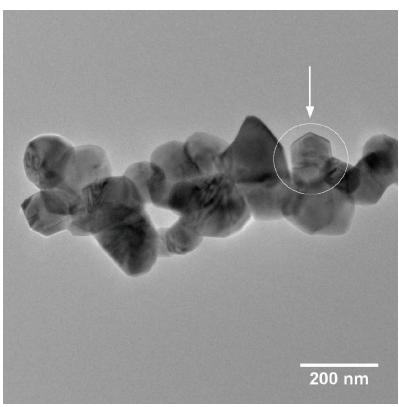

(j)

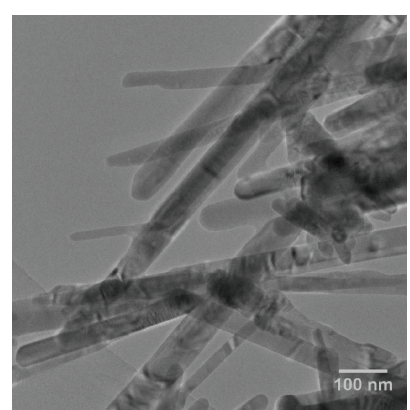

(c)

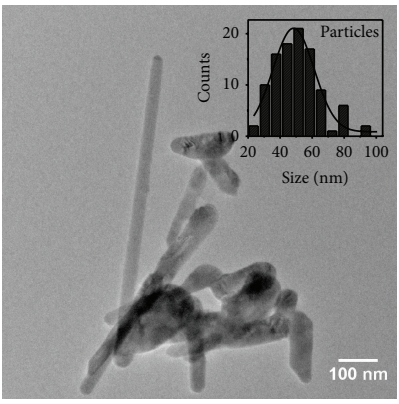

(g)

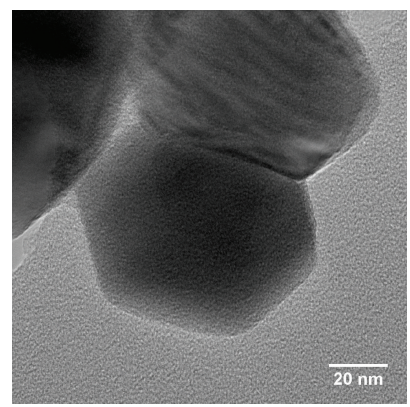

(k)

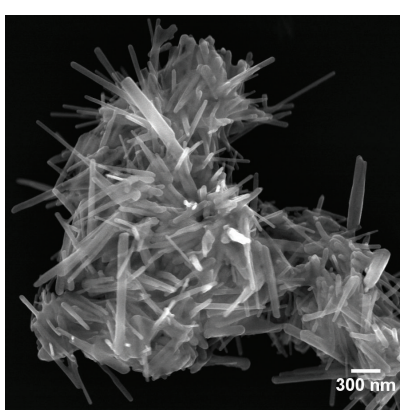

(d)

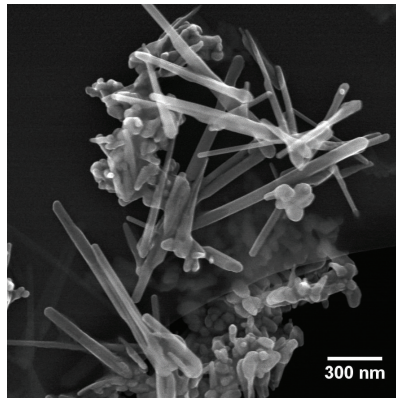

(h)

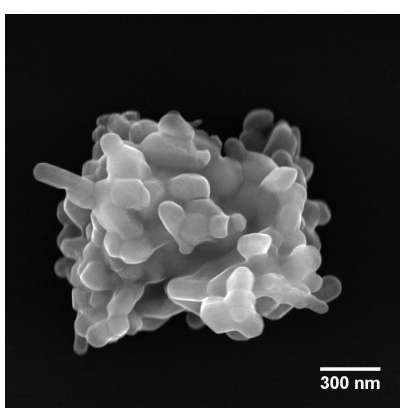

(l)

FIgure 1: TEM and SEM images of $\mathrm{ZnO}$ samples fabricated at $(\mathrm{a}-\mathrm{d}) 300^{\circ} \mathrm{C}$, (e-h) $400^{\circ} \mathrm{C}$, and (i-l) $500^{\circ} \mathrm{C}$. The insets on (a, b, e-g, and i) represent the size distribution of the structures. The arrow in $(\mathrm{j})$ shows a hexagonal-like crystal present in the sample at $500^{\circ} \mathrm{C}$.

TABLE 2: ZnO vibrational modes and relative intensity of the bands.

\begin{tabular}{|c|c|c|c|c|c|c|c|c|}
\hline \multirow{2}{*}{$\begin{array}{l}\text { Mode } \\
E_{2 H}-E_{2 L}\end{array}$} & \multicolumn{2}{|c|}{$\begin{array}{c}\text { Reference } \\
\text { Wavelength } I_{i} / I_{0}\left(\mathrm{~cm}^{-1}\right)\end{array}$} & \multicolumn{2}{|c|}{$\begin{array}{c}300^{\circ} \mathrm{C} \\
\text { Wavelength } I_{i} / I_{0}\left(\mathrm{~cm}^{-1}\right)\end{array}$} & \multicolumn{2}{|c|}{$\begin{array}{c}400^{\circ} \mathrm{C} \\
\text { Wavelength } I_{i} / I_{0}\left(\mathrm{~cm}^{-1}\right)\end{array}$} & \multicolumn{2}{|c|}{$\begin{array}{c}500^{\circ} \mathrm{C} \\
\text { Wavelength } I_{i} / I_{0}\left(\mathrm{~cm}^{-1}\right)\end{array}$} \\
\hline & 328 & 26.5 & 327 & 51.5 & 331 & 26.9 & 332 & 15.5 \\
\hline$A_{1}(\mathrm{TO})$ & 376 & 57.8 & 386 & 15.9 & 390 & 7.30 & 387 & 6.10 \\
\hline$E_{1}(\mathrm{TO})$ & 410 & 19.4 & 428 & 24.1 & 431 & 14.9 & 434 & 30.0 \\
\hline$E_{2}$ (high) & 437 & 100 & 436 & 100 & 439 & 100 & 439 & 100 \\
\hline$E_{2 H}+E_{2 L}$ & 536 & 4.50 & 528 & 4.50 & 533 & 10.3 & 538 & 3.50 \\
\hline$A_{1}(\mathrm{LO})$ & - & - & 573 & 20.7 & 572 & 7.60 & 573 & 3.80 \\
\hline$E_{1}(\mathrm{LO})$ & - & - & - & - & 583 & 4.70 & 585 & 3.80 \\
\hline
\end{tabular}

All the vibrational modes correspond to the ones predicted by the theory and experiments reported in the literature [25, 27-29]. Table 2 presents the vibrational peaks and the respective percentage of relative intensity $\left(I_{i} / I_{0}\right)$, where $I_{0}$ is the intensity of the most intense and characteristic band
$E_{2}$ (high) antisymmetric, which is related to oxygen attached to zinc atoms in the tetrahedral configuration. Longitudinal optical modes $A_{1}(\mathrm{LO})$ and $E_{1}(\mathrm{LO})$ are not evident in the obtained material, since they are only visible when the axis $c$ of the wurtzite structure is parallel to the surface. For 


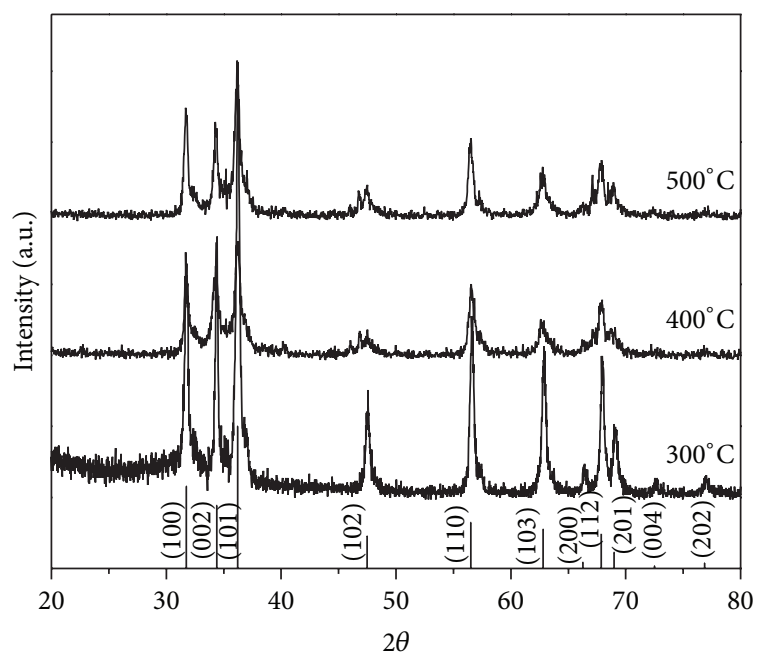

FIGURE 2: XRD diffractogram of $\mathrm{ZnO}$ nanostructure samples fabricated at 300,400 , and $500^{\circ} \mathrm{C}$, respectively. This growth can be observed from the presence of the peaks at 31.76, 34.32, 36.22, 47.56, $56.58,62.84,66.44,68.04,69.12,72.7$, and 76.94 which correspond to (100), (002), (101), (102), (110), (103), (200), (112), (201), (004), and (202) orientations, respectively. As shown in the XRD data, the (101) direction is the preferred orientation for the three samples. Reference corresponds to JCPDS card number 36-1451.

the nanostructured material there are no constraints for the longitudinal optical modes due to the fact that the structures are randomly organized.

The bands located between the interval of 327 to $332 \mathrm{~cm}^{-1}$ and 528 to $538 \mathrm{~cm}^{-1}$ correspond to the multiphononic modes of second order, which are expressed with $\left[E_{2}\right.$ (high) $E_{2}($ low $\left.)\right]$ and $\left[E_{2}\right.$ (high) $+E_{2}($ low $\left.)\right]$, respectively and do not differ from other reports.

The nanorod morphology constrains the vibrational degrees of freedom of the molecules. The nanoparticle morphology allows a greater freedom in the vibration of the characteristic mode $E_{2}$ (high). The $A_{1}$ longitudinal and transversal modes are associated to parallel displacement of oxygen atoms on the $c$ axis and are more intense for the $300^{\circ} \mathrm{C}$ sample since the structure is preferentially oriented in this direction. As a result of the increase in the temperature, the $A_{1}$ modes decrease due to the oxygen deficiency. In addition, the presence of the mode $E_{1}(\mathrm{LO})$ is more prominent with the increase in the temperature which is related to an oxygen deficiency [29-31].

3.3. Optical Absorption. Figure 4(a) shows the absorbance spectrum as a function of the wavelength for the sintered materials at 300,400 , and $500^{\circ} \mathrm{C}$. From these results, the forbidden energy band $E_{g}$ is established according to Tauc's expression:

$$
A h \nu=B\left(h v-E_{g}\right)^{m}
$$

where $A$ is the absorption, $B$ is a constant, and $m$ is taken as $1 / 2$ for direct-gap materials. From the dependence of $(A h \nu)^{2}$ with the energy (Figure $4(\mathrm{~b})$ ) the energy gap in the material

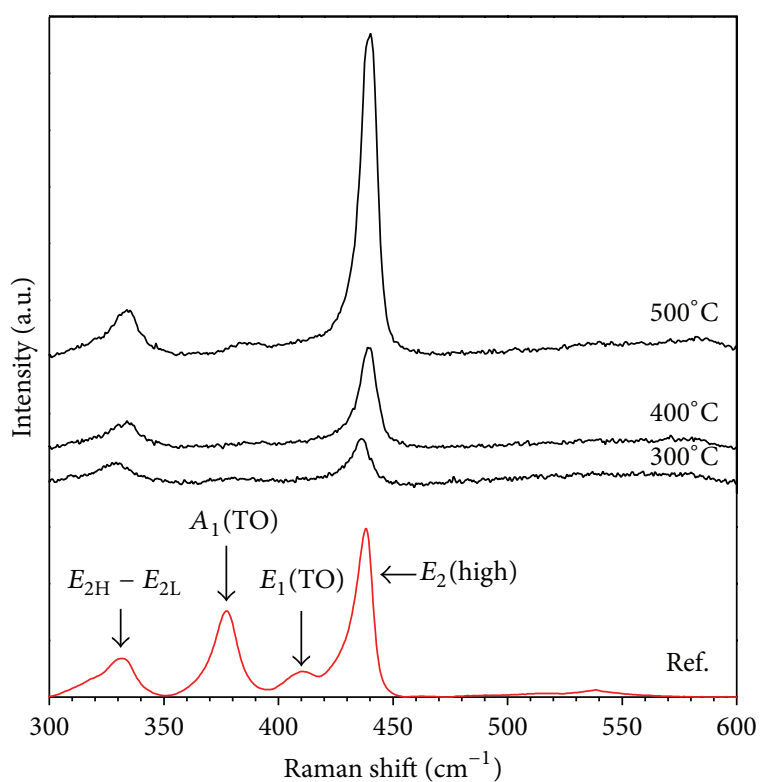

(a)

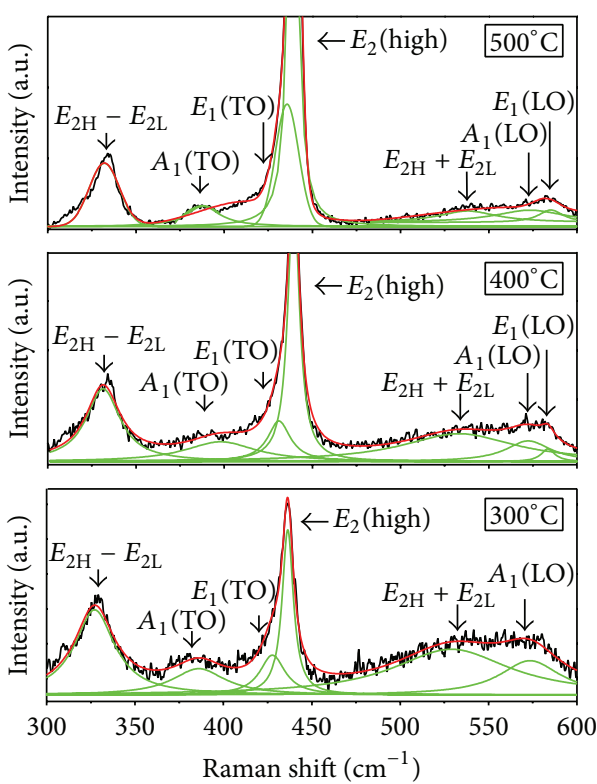

(b)

Figure 3: (a) Raman spectra of $\mathrm{ZnO}$ samples fabricated at 300, 400 , and $500^{\circ} \mathrm{C}$, respectively, and reference. (b) Raman spectra at room temperature of $\mathrm{ZnO}$ samples fabricated at 300,400 , and $500^{\circ} \mathrm{C}$, respectively. $\mathrm{ZnO}$ phonon modes as well as molecular vibrations are observed for comparison, and the spectrum of $\mathrm{ZnO}$ reference is shown.

is obtained. The energies determined for the materials were $3.21 \pm 0.04,3.20 \pm 0.07$, and $3.17 \pm 0.03 \mathrm{eV}$ for 300,400 , and $500^{\circ} \mathrm{C}$, respectively.

A small decrease in the $E_{g}$ value with the increase in the temperature is observed. The values hereby reported are lower than the one for the bulk material of $3.37 \mathrm{eV}$. This is opposite to the expected outcome for nanostructures and it may be due to the presence of defects and impurity levels 


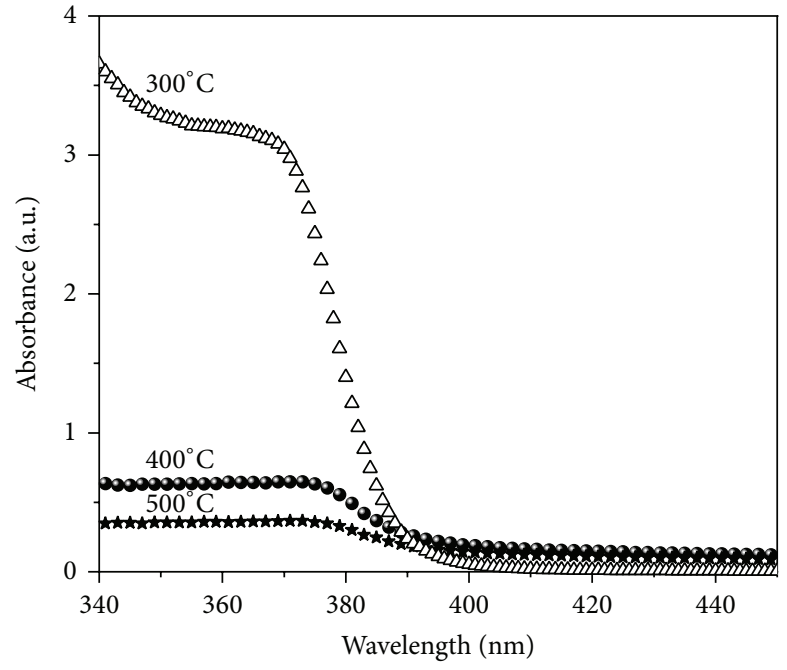

(a)

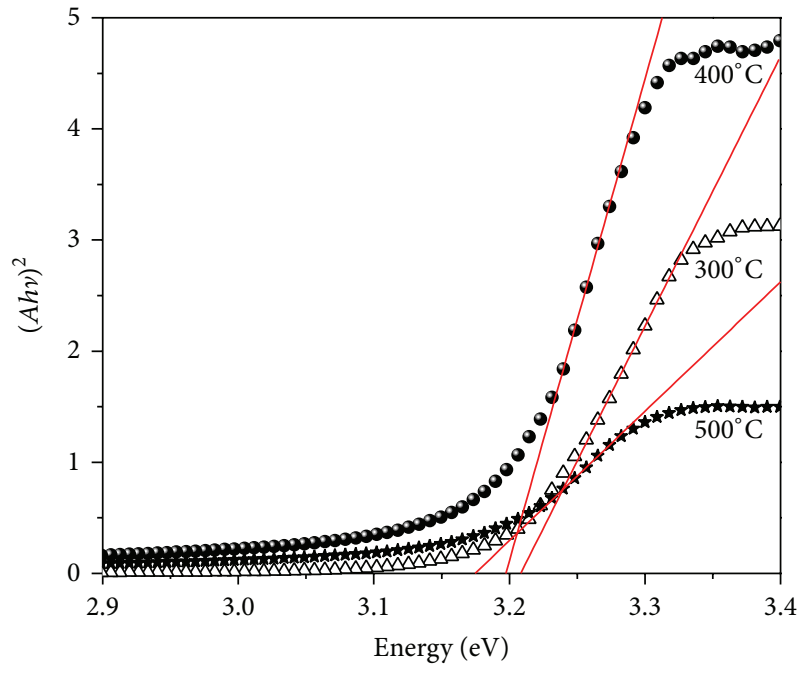

(b)

Figure 4: (a) Absorbance spectrum of $\mathrm{ZnO}$ sintered at 300, 400, and $500^{\circ} \mathrm{C}$, respectively. (b) $(A h \nu)^{2}$ versus energy. The solid lines represent the linear fit.

inside the band gap and is in good agreement with other reports $[16,21,22,32]$.

\section{Conclusions}

The thermal decomposition of zinc acetate allows the production of $\mathrm{ZnO}$ nanorods at $300^{\circ} \mathrm{C}$ and hexagonal-like nanoparticles at $500^{\circ} \mathrm{C}$. Increasing temperatures favor the homogeneous crystallization among the different polar and nonpolar planes, as well as promoting the morphological transformation from nanorods to nanoparticles. A higher temperature creates more nucleation sites in which nanoparticles can start to grow. The slow heating rate is responsible for the loss of water and the oxygen deficiency rise. The average diameter of the nanorods is comparable to the crystallite size. Increments in the temperature reduce the size of the crystalline domains. The sintered material at $300^{\circ} \mathrm{C}$ shows a better crystalline organization in comparison to the obtained material at 400 and $500^{\circ} \mathrm{C}$. The rise of the temperature increases the presence of structural defects, which are demonstrated with the increase of Raman mode $E_{1}(\mathrm{LO})$ and the reduction of the $A_{1}$ modes, related to the presence of oxygen vacancies. The energy band gap decreases with the temperature and in all the cases is lower than the bulk value.

\section{Conflict of Interests}

The authors declare that there is no conflict of interests regarding the publication of this paper.

\section{Acknowledgments}

This work was carried out with the support of the Research Information System HERMES from the National University of Colombia, Project no. 15875. The authors wish to thank the plasma physics, material optical properties, and nanostructured and functional materials laboratories from The National University of Colombia-Manizales for the XRD, Raman, and UV-Vis measurements. The authors wish to thank as well the University of Texas at San Antonio and The Kleberg Advanced Microscopy Laboratory where the TEM and SEM measurements were carried out.

\section{References}

[1] O. Lupan, G. A. Emelchenko, V. V. Ursaki et al., "Synthesis and characterization of $\mathrm{ZnO}$ nanowires for nanosensor applications," Materials Research Bulletin, vol. 45, no. 8, pp. 1026-1032, 2010.

[2] K.-M. Kim, H.-R. Kim, K.-I. Choi, H.-J. Kim, and J.-H. Lee, "ZnO hierarchical nanostructures grown at room temperature and their $\mathrm{C}_{2} \mathrm{H}_{5} \mathrm{OH}$ sensor applications," Sensors and Actuators B: Chemical, vol. 155, no. 2, pp. 745-751, 2011.

[3] M. M. Arafat, B. Dinan, S. A. Akbar, and A. S. M. A. Haseeb, "Gas sensors based on one dimensional nanostructured metaloxides: a review," Sensors, vol. 12, no. 6, pp. 7207-7258, 2012.

[4] P. C. Tao, Q. Feng, J. Jiang et al., "Electroluminescence from $\mathrm{ZnO}$ nanowires homojunction LED grown on Si substrate by simple chemical vapor deposition," Chemical Physics Letters, vol. 522, pp. 92-95, 2012.

[5] C. Luan, A. Vaneski, A. S. Susha et al., "Facile solution growth of vertically aligned $\mathrm{ZnO}$ nanorods sensitized with aqueous CdS and CdS equantum dots for photovoltaic applications," Nanoscale Research Letters, vol. 6, p. 340, 2011.

[6] N. Singh, R. M. Mehra, A. Kapoor, and T. Soga, "ZnO based quantum dot sensitized solar cell using CdS quantum dots," Journal of Renewable and Sustainable Energy, vol. 4, no. 1, Article ID 013110, 2012.

[7] M. Navaneethan, J. Archana, M. Arivanandhan, and Y. Hayakawa, "Functional properties of amine-passivated $\mathrm{ZnO}$ nanostructures and dye-sensitized solar cell characteristics," Chemical Engineering Journal, vol. 213, pp. 70-77, 2012. 
[8] G. C. Yi, T. Yatsui, and M. Ohtsu, " $\mathrm{ZnO}$ nanorods and their heterostructures for electrical and optical nanode-vice applications," Comprehensive Nanoscience and Technology: Nanomaterials, vol. 1, pp. 335-374, 2011.

[9] C. Ma, Z. Zhou, H. Wei, Z. Yang, Z. Wang, and Y. Zhang, "Rapid large-scale preparation of zno nanowires for photocatalytic application," Nanoscale Research Letters, vol. 6, article 536, 5 pages, 2011.

[10] Z. Han, L. Liao, Y. Wu, H. Pan, S. Shen, and J. Chen, "Synthesis and photocatalytic application of oriented hierarchical $\mathrm{ZnO}$ flower-rod architectures," Journal of Hazardous Materials, vol. 217-218, pp. 100-106, 2012.

[11] L. Sun, D. Zhao, Z. Song et al., "Gold nanoparticles modified $\mathrm{ZnO}$ nanorods with improved photocatalytic activity," Journal of Colloid and Interface Science, vol. 363, no. 1, pp. 175-181, 2011.

[12] Y. Zhang, M. K. Ram, E. K. Stefanakos, and D. Y. Goswami, "Synthesis, characterization, and applications of $\mathrm{ZnO}$ nanowires," Journal of Nanomaterials, vol. 2012, Article ID 624520, 22 pages, 2012.

[13] E. Darezereshki, M. Alizadeh, F. Bakhtiari, M. Schaffie, and M. Ranjbar, "A novel thermal decomposition method for the synthesis of $\mathrm{ZnO}$ nanoparticles from low concentration $\mathrm{ZnSO}_{4}$ solutions," Applied Clay Science, vol. 54, no. 1, pp. 107-111, 2011.

[14] R.-C. Wang and C.-C. Tsai, "Efficient synthesis of $\mathrm{ZnO}$ nanoparticles, nanowalls, and nanowires by thermal decomposition of zinc acetate at a low temperature," Applied Physics A, vol. 94, no. 2, pp. 241-245, 2009.

[15] A. V. Ghule, K. Ghule, C.-Y. Chen et al., "In situ thermo-TOFSIMS study of thermal decomposition of zinc acetate dihydrate," Journal of Mass Spectrometry, vol. 39, no. 10, pp. 1202-1208, 2004.

[16] S. Labuayai, V. Promarak, and S. Maensiri, "Synthesis and optical properties of nanocrystalline $\mathrm{ZnO}$ powders prepared by a direct thermal decomposition route," Applied Physics A, vol. 94, no. 4, pp. 755-761, 2009.

[17] C.-C. Lin, W.-H. Lin, and Y.-Y. Li, "Field emission properties of $\mathrm{ZnO}$ nanowires synthesized by thermal decomposition process," Journal of Physics D: Applied Physics, vol. 41, no. 22, Article ID 225411, 2008.

[18] C.-C. Lin and Y.-Y. Li, "Synthesis of ZnO nanowires by thermal decomposition of zinc acetate dihydrate," Materials Chemistry and Physics, vol. 113, no. 1, pp. 334-337, 2009.

[19] X. Su, Z. Zhang, Y. Wang, and M. Zhu, "Synthesis and photoluminescence of aligned $\mathrm{ZnO}$ nanorods by thermal decomposition of zinc acetate at a substrate temperature of $\sim 250^{\circ} \mathrm{C}$," Journal of Physics D: Applied Physics, vol. 38, no. 21, pp. 39343937, 2005.

[20] H. Morkos and U. Ozgur, Zinc Oxide Fundamentals, Materials and Device Technology, Alemania, Wiley-VCH, Alemania, Germany, 2009.

[21] B. Madavali, H. S. Kim, and S. J. Hong, "Thermally decomposition of high quality ower-like $\mathrm{ZnO}$ nanorods from zinc acetate dihydrate," Materials Letters, vol. 132, pp. 342-345, 2014.

[22] M. Farbod and E. Jafarpoor, "Hydrothermal synthesis of different colors and morphologies of $\mathrm{ZnO}$ nanostructures and comparison of their photocatalytic properties," Ceramics International, vol. 40, pp. 6605-6610, 2014.

[23] N. Shakti, A. Prakash, T. Mandal, and M. Katiyar, "Processing temperature depe ndent morphological and optical properties of $\mathrm{ZnO}$ nanorods," Materials Science in Semiconductor Processing, vol. 20, pp. 55-60, 2014.
[24] R. Saravanan, E. Thirumal, V. K. Gupta, V. Narayanan, and A. Stephen, "The photocatalytic activity of $\mathrm{ZnO}$ prepared by simple thermal decomposition method at various temperatures," Journal of Molecular Liquids, vol. 177, pp. 394-401, 2013.

[25] M. S. Soosen, K. Jiji, C. Anoop, and K. C. George, "Optical phonon confinement in $\mathrm{ZnO}$ nanorods and nanotubes," Indian Journal of Pure and Applied Physics, vol. 48, no. 10, pp. 703-708, 2010.

[26] D. H. Zhang, Z. Y. Xue, and Q. P. Wang, "The mechanisms of blue emission from $\mathrm{ZnO}$ films deposited on glass substrate by r.f. magnetron sputtering," Journal of Physics D: Applied Physics, vol. 35, no. 21, pp. 2837-2840, 2002.

[27] S. Musić, D. Dragčević, S. Popović, and M. Ivanda, "Precipitation of $\mathrm{ZnO}$ particles and their properties," Materials Letters, vol. 59, no. 19-20, pp. 2388-2393, 2005.

[28] H. K. Yadav, K. Sreenivas, V. Gupta, J. F. Scott, and R. S. Katiyar, "Raman spectroscopy and dielectric studies of multiple phase transitions in ZnO:Ni," Applied Physics Letters, vol. 92, Article ID 122908, 2008.

[29] P. Kanti Samanta and A. Kumar Bandyopadhyay, "Chemical growth of hexagonal zinc oxide nanorods and their optical properties," Applied Nanoscience, vol. 2, pp. 111-117, 2012.

[30] K. J. Chen, T. H. Fang, F. Y. Hung et al., "The crystallization and physical properties of Al-doped $\mathrm{ZnO}$ nanoparticles," Applied Surface Science, vol. 254, no. 18, pp. 5791-5795, 2008.

[31] U. Pal, J. G. Serrano, P. Santiago, G. Xiong, K. B. Ucer, and R. T. Williams, "Synthesis and optical properties of $\mathrm{ZnO}$ nanostructures with different morphologies," Optical Materials, vol. 29, no. 1, pp. 65-69, 2006.

[32] A. K. Zak, M. E. Abrishami, W. H. A. Majid, R. Yousefi, and S. M. Hosseini, "Effects of annealing temperature on some structural and optical properties of $\mathrm{ZnO}$ nanoparticles prepared by a modified sol-gel combustion method," Ceramics International, vol. 37, no. 1, pp. 393-398, 2011. 

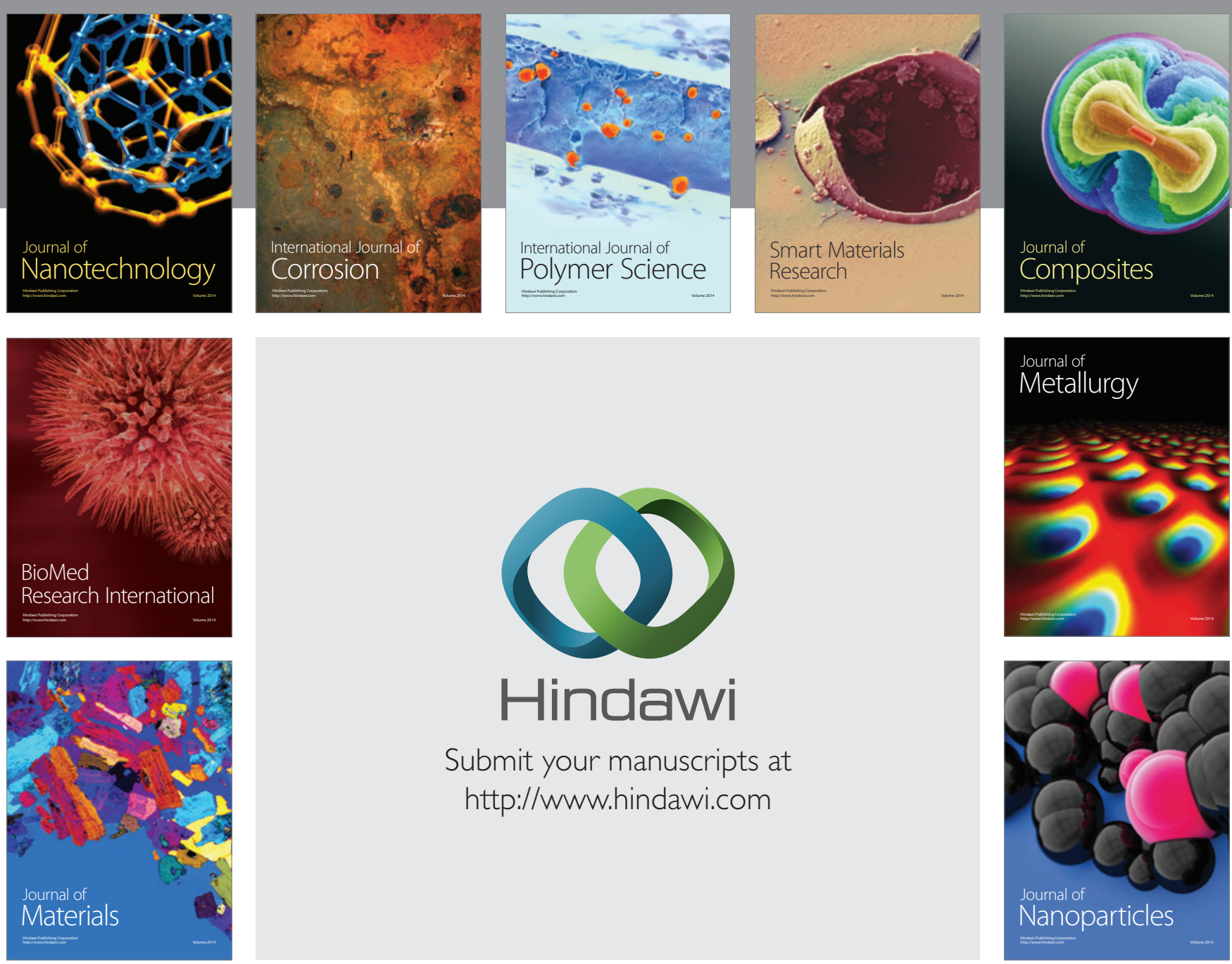

Submit your manuscripts at http://www.hindawi.com
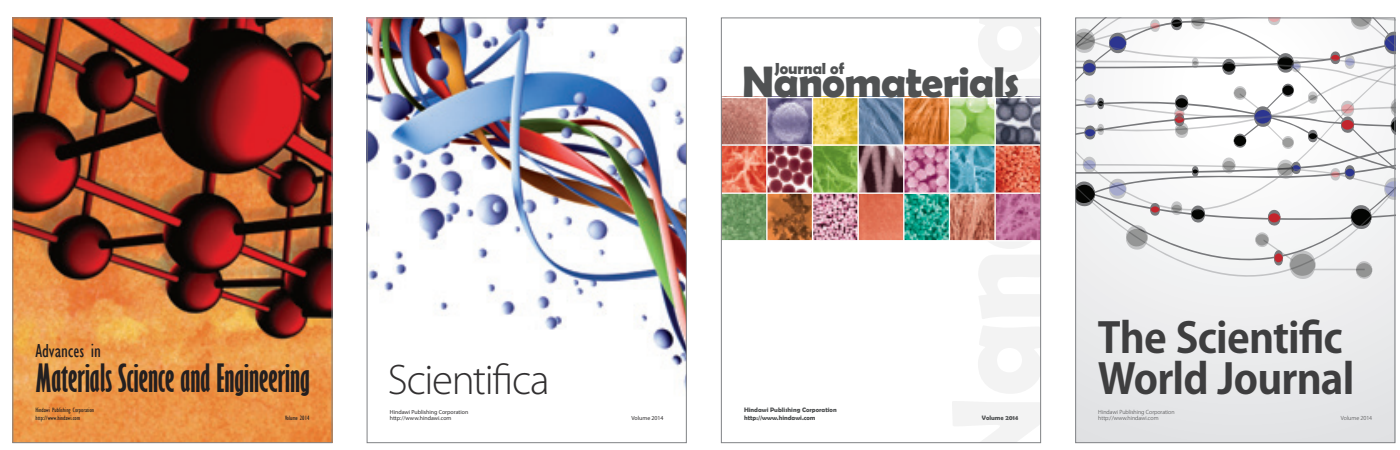

\section{The Scientific World Journal}
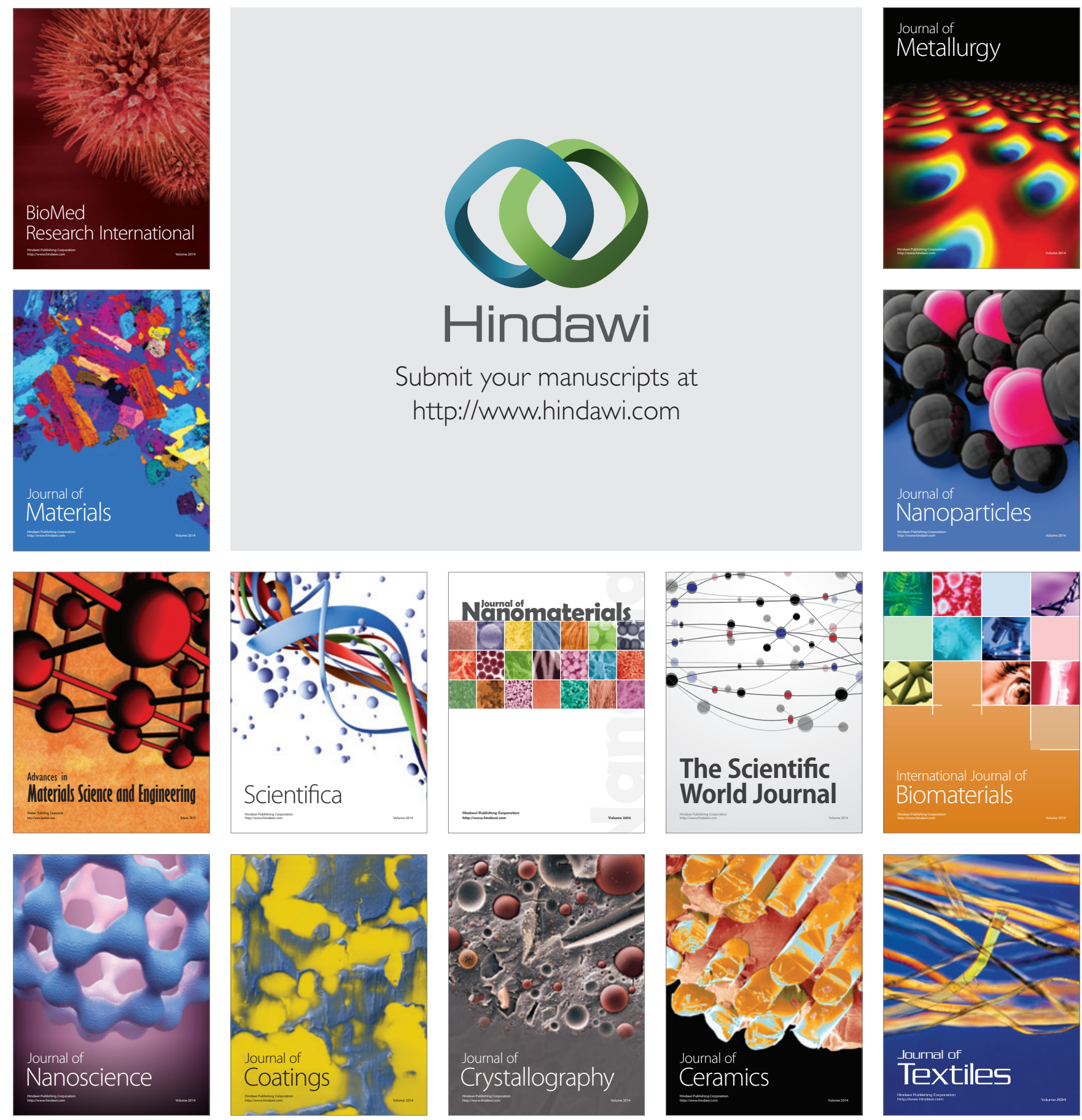